\title{
EROS Resources for the Classroom
}

The U.S. Geological Survey (USGS) Earth Resources Observation and Science (EROS) Center has several educational resources that demonstrate how satellite imagery is used to understand our changing world.
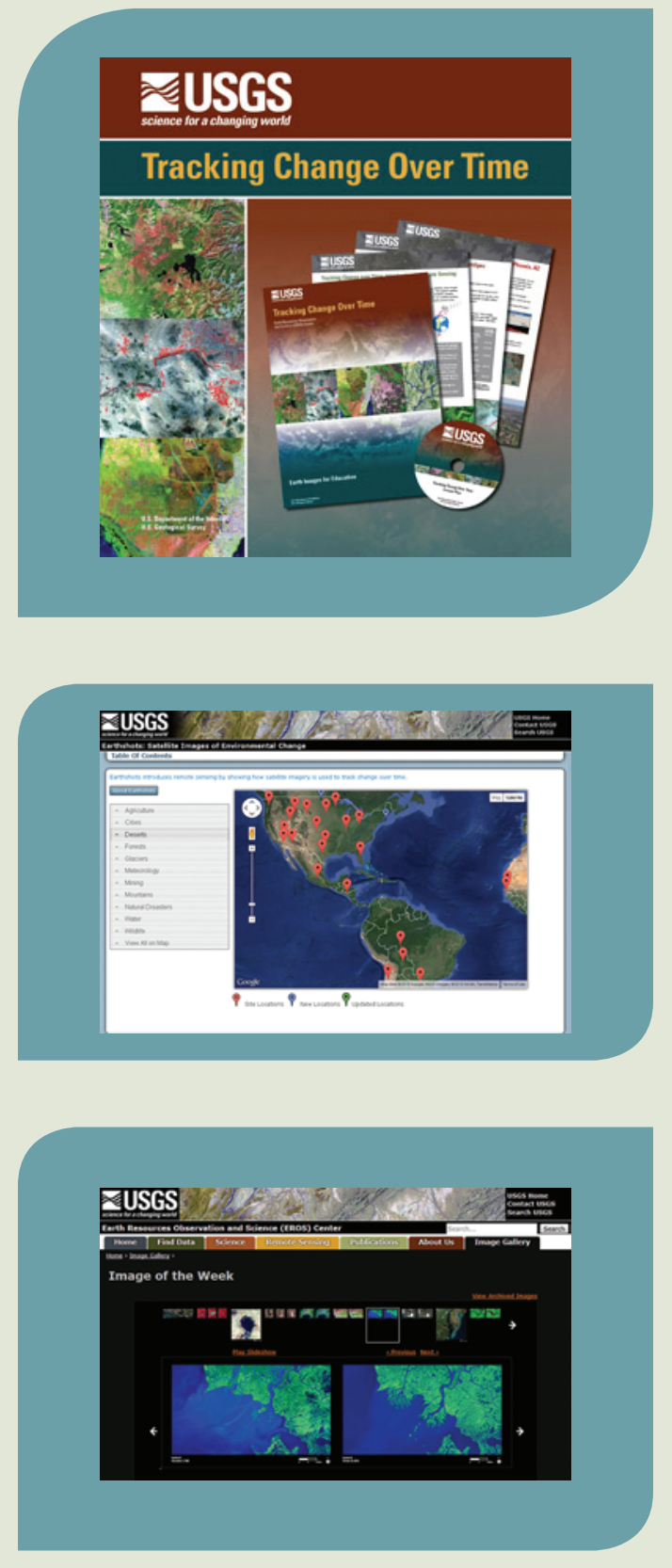

\section{Tracking Change Over Time}

Enhance students' learning of geography, map reading, Earth science, and problem solving by observing landscape changes as seen from space. Using the free software MultiSpec, students can compare Landsat images from multiple years to better understand how scientists use satellite data to identify changes to the Earth's surface. Intended for grades $5-8$, the lesson plan is flexible and may be used as a student self-guided tutorial or as a teacher-led class lesson.

The lesson plan includes an introduction to satellite images, an introduction to remote sensing, and instructions on how to use MultiSpec, as well as modules that provide greater detail for specific areas using remote sensing.

\section{http://eros.usgs.gov/educational-activities}

\section{Earthshots-Satellite Images of Environmental Change}

Earthshots shows how satellite imagery is used to track change over time. Each Earthshots page features a different location and explains the changes that the satellite images reveal. Natural disasters, urban growth, and glaciers are just a few land change topics covered in Earthshots. The "About Earthshots" page shows how the Landsat satellites work and what the colors in the images mean.

http://earthshots.usgs.gov

\section{Image of the Week}

Whether natural or human-caused, changes on the surface of the Earth are happening all the time. The Image of the Week gallery on the USGS EROS Center Web site shows how these changes have local, regional, national, and even global effects. Brief descriptions clearly explain the changes seen in the images. A poster is available to download and can be freely used as needed. Keep checking this page for new examples of the changing Earth as seen from satellite images.

http://eros.usgs.gov/imagegallery/image-week-2 


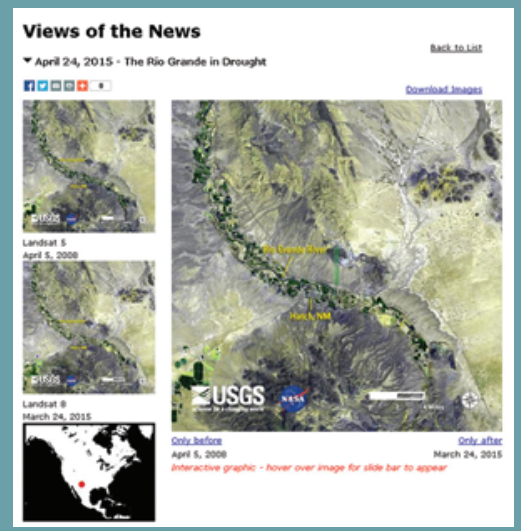

\section{Views of the News}

Human impact on the land sometimes makes big news. Natural disasters also highlight the need to monitor the changing land from space. Visit the Views of the News gallery on the USGS EROS Center Web site for examples of how unbiased views from space help make sense of these news stories. At this page, using the image slider makes natural and human-caused land changes crystal clear. A brief description usually accompanies a link to more detailed information.

http://eros.usgs.gov/views-news

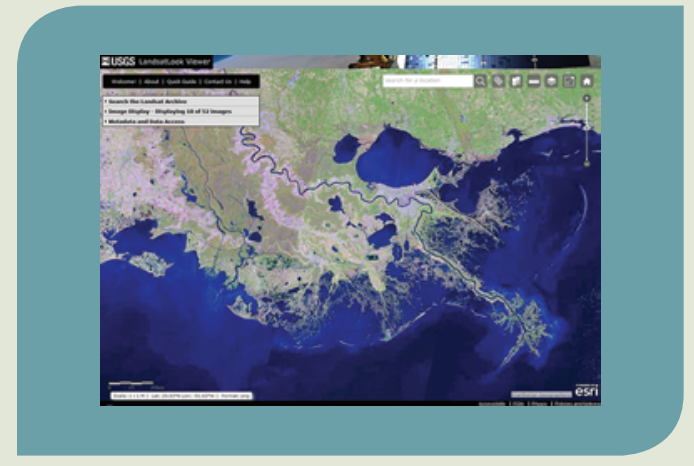

\section{LandsatLook Viewer}

Interactively explore the Landsat archive from a Web browser using the LandsatLook Viewer. The LandsatLook Viewer displays natural color images for all Landsat 1-8 images in the Landsat archive. The viewer allows screen captures of the viewing window. This allows for easy visualization of the archived Landsat imagery without the need for specialized software or technical expertise. LandsatLook makes it easy to compare images and see changes over time.

http://landsatlook.usgs.gov/

\section{Contact Information}

U.S. Geological Survey

Earth Resources Observation and

Science (EROS) Center

47914 252nd Street

Sioux Falls, SD 57198-0001
Tel: 800-252-4547

Tel: 605-594-6151

Email: custserv@usgs.gov 